\title{
Multiple Drug Hypersensitivity
}

\author{
Werner J. Pichler ${ }^{\mathrm{a}}$ Yuttana Srinoulprasert ${ }^{c} \quad$ James Yun $^{\mathrm{d}}$ Oliver Hausmann ${ }^{\mathrm{a}}$ b \\ ${ }^{a}$ ADR-AC, Bern, and ${ }^{b}$ Löwenpraxis, Luzern, Switzerland; ' Department of Immunology, Faculty of Medicine, Siriraj \\ Hospital, Mahidol University, Bangkok, Thailand; ${ }^{2}$ Department of Clinical Immunology, Royal Prince Alfred Hospital, \\ Sydney, NSW, Australia
}

\section{Keywords}

Drug hypersensitivity · Multiple drug hypersensitivity . Drug rash with eosinophilia and systemic symptoms . Maculopapular exanthema $\cdot \mathrm{p}$-i concept

\begin{abstract}
Multiple drug hypersensitivity (MDH) is a syndrome that develops as a consequence of massive T-cell stimulations and is characterized by long-lasting drug hypersensitivity reactions (DHR) to different drugs. The initial symptoms are mostly severe exanthems or drug rash with eosinophilia and systemic symptoms (DRESS). Subsequent symptoms due to another drug often appear in the following weeks, overlapping with the first DHR, or months to years later after resolution of the initial presentation. The second DHR includes exanthema, erythroderma, DRESS, Stevens-Johnson syndrome/toxic epidermal necrolysis (SJS/TEN), hepatitis, and agranulocytosis. The eliciting drugs can be identified by positive skin or in vitro tests. The drugs involved in starting the $\mathrm{MDH}$ are the same as for DRESS, and they are usually given in rather high doses. Fixed drug combination therapies like sulfamethoxazole/trimethoprim or piperacillin/tazobactam are frequently involved in $\mathrm{MDH}$, and $30-40 \%$ of patients with severe DHR to combination therapy show T-cell reactions to both components. The drug-induced T-cell stimulation appears to be due to the $p$-i mechanism. Importantly, a perma-
\end{abstract}

\begin{tabular}{ll}
\hline KARGER & $\begin{array}{l}\text { ( } 2017 \text { The Author(s) } \\
\text { Published by S. Karger AG, Basel Oparger }\end{array}$ \\
E-Mail karger@karger.com & \\
www.karger.com/iaa & This article is licensed under the Creative Commons Attribution- \\
& $\begin{array}{l}\text { NonCommercial-NoDerivatives 4.0 International License (CC BY- } \\
\text { NC-ND) (http://www.karger.com/Services/OpenAccessLicense). } \\
\text { Usage and distribution for commercial purposes as well as any dis- } \\
\text { tribution of modified material requires written permission. }\end{array}$
\end{tabular}

nent T-cell activation characterized by PD-1+/CD38+ expression on $\mathrm{CD} 4+/ \mathrm{CD} 25^{\text {low }} \mathrm{T}$ cells can be found in the circulation of patients with MDH for many years. In conclusion, $\mathrm{MDH}$ is a drug-elicited syndrome characterized by a long-lasting hyperresponsiveness to multiple, structurally unrelated drugs with clinically diverse symptoms. @ 2017 The Author(s)

Published by S. Karger AG, Basel

\section{Introduction}

The term multiple drug hypersensitivity $(\mathrm{MDH})$ was coined by Sullivan et al. [1], who described in 1986 some patients with reactions to chemically distinct antibiotics. They noted that $13 \%$ of penicillin-allergic patients developed a drug reaction to nonpenicillin antibiotics like sulfonamides, tetracyclines, erythromycin, vancomycin, and aminoglycosides, with rash, anaphylaxis, drug fever, Stevens-Johnson syndrome/toxic epidermal necrolysis (SJS/TEN), and serum sickness, while only $1.4 \%$ reacted if no drug allergy history existed. Later it was found that patients with a history of a previous drug allergy had a 9.4-fold increased risk of developing a drug allergy to a distinct antibiotic compared to patients without a drug allergy [2]. In addition, $10 \%$ of the family members of drug-allergic patients developed a drug allergy [3]. 
Table 1. Distinction between DRESS, flare-up reactions, $\mathrm{MDH}$, and intolerance reactions

\begin{tabular}{|c|c|c|c|c|}
\hline & DRESS $^{\mathrm{a}}$ & Flare-up ${ }^{b}$ & $\mathrm{MDH}$ & NSAID intolerance \\
\hline Drug: the reactions occur to & first & second & second or third & various NSAID \\
\hline Drug exposure before the symptoms & $>10$ days & $2-4 \mathrm{~h}$ to 2 days & $>3$ days & $<1 \mathrm{~h}$ \\
\hline Expansion of drug-induced $\mathrm{T}$ cells & days or weeks & only activation, no expansion & days or weeks & $\mathrm{T}$ cells are not involved \\
\hline Symptoms & $\begin{array}{l}\text { DRESS/ } \\
\text { exanthema }\end{array}$ & identical to the first DHR & $\begin{array}{l}\text { similar to or different from } \\
\text { the first DHR }\end{array}$ & $\begin{array}{l}\text { urticaria, anaphylaxis, } \\
\text { bronchospasm }\end{array}$ \\
\hline Sensitization (skin tests/LTT) & yes & no & yes (to 2 or more drugs) & no \\
\hline Persistence & $\mathrm{no}^{\mathrm{a}}$ & no & yes & $\mathrm{yes}^{\mathrm{c}}$ \\
\hline
\end{tabular}

DHR, drug hypersensitivity reaction; DRESS, drug rash with eosinophilia and systemic symptoms; MDH, multiple drug hypersensitivity; NSAID, nonsteroidal anti-inflammatory drugs; LTT, lymphocyte transformation tests. ${ }^{a}$ Most patients with DRESS do not develop MDH. ${ }^{b}$ In flare-up reactions, similar symptoms reappear upon a short exposure to a new drug days to weeks after the acute DHR but, after a while (i.e., weeks to months), the hypersensitivity disappears and the drugs are able to be tolerated. Hence the reactivity is not persistent. Some flare-up reactions may be due to viral reactivations. ${ }^{c}$ Persistence is not related to an immune reaction.

Later, the term MDH was also used for reactions observed in patients suffering from intolerance presenting with urticaria, angioedema, and/or anaphylaxis to structurally distinct, but functionally related, nonsteroidal anti-inflammatory drugs $[4,5]$. However, intolerance reactions to nonsteroidal anti-inflammatory drugs are not immune mediated but rather they are related to the pharmacological properties of all nonsteroidal anti-inflammatory drugs (i.e., inhibition of cyclooxygenase). To differentiate $\mathrm{MDH}$ from intolerance reactions, it was proposed that the term $\mathrm{MDH}$ should be used only for clinically well-defined drug hypersensitivity reactions (DHR) elicited by 2 or more chemically distinct drugs, where their involvement has been proven by skin tests or in vitro tests $[6,7]$ (Table 1 ).

The T-cell activations in MDH are not due to crossreactivity. Cloning of drug-reactive $\mathrm{T}$ cells of a patient with DHR to 4 different drugs revealed that each T-cell clone was highly specific for a single drug, and no crossreactive $\mathrm{T}$-cell clones were found [8]. Moreover, drugreactive $\mathrm{T}$ cells of a patient with $\mathrm{MDH}$ were found to have a distinct function with a distinct cytokine production upon drug-specific stimulation [9]. This is consistent with the observation that patients with $\mathrm{MDH}$ to different drugs develop diverse clinical manifestations [6, $7,10]$.

Here we summarize the clinical and immunological aspects of MDH based on clinical data of 31 patients with $\mathrm{MDH}$ and our database of lymphocyte transformation tests (LTT). MDH is a syndrome that persists long after the drug treatment has been stopped and can result in highly different clinical manifestations. It is distinct from flare-up reactions, drug rash with eosinophilia and systemic symptoms (DRESS), and intolerance reactions (Ta- ble 1). Here we review this syndrome with the aim of raising awareness and stimulating research on this still widely unknown syndrome.

\section{MDH, DRESS, and Flare-Up Reactions}

Reports on $\mathrm{MDH}$ are rare. Gex-Collet et al. [6] proposed that MDH should be proven by positive skin and/ or in vitro tests to distinct drugs. We observed previously that about $10 \%$ of patients with severe drug hypersensitivity have additional reactivity to structurally unrelated drugs in vivo and/or in vitro [7]. This is similar to the incidence of MDH of $13 \%$ described by Sullivan et al. [1]. Studer et al. [11] used cutaneous symptoms and skin test reactivity to at least 2 chemically distinct substances as criteria for $\mathrm{MDH}$. The incidence of $\mathrm{MDH}$ was much lower in that study $(0.6 \%)$, probably because most of the patients selected from their database might have had just mild cutaneous symptoms. Importantly, clinical studies of $\mathrm{MDH}[6-8,10,11]$ have shown that the initial manifestation can be exclusive severe exanthema or erythroderma rather than DRESS; for example, in the series of Studer et al. [11], only 4 out of 11 patients with MDH had DRESS as the initial manifestation, and in the study of Daubner et al. [8] the number was only 4 out of 7 .

A large collection of recurrent drug reactions was published recently by Picard et al. [10]. They found that 15 out of $60(25 \%)$ patients with prior DRESS experienced relapses with rash, eosinophilia, and/or elevated liver function tests to new drugs 2-240 days after the acute DRESS. Regretfully, sensitizations to the involved drugs were not documented and thus their data do not differentiate between real MDH and "flare-up" reactions. 
Table 2. Clinical manifestations of first and follow-up manifestations of $\mathrm{MDH}$

\begin{tabular}{ll}
\hline Clinical manifestation of DHR (first episode) $(n=31)$ & Clinical manifestation of DHR (second/third episode) \\
\hline Severe exanthema/erythroderma $(n=13)$ & - Exanthema/erythrodermia \\
DRESS $(n=12)$ & - DRESS (often with different organ involvements including hepatitis, \\
Erythema multiforme major $(n=3)$ & nephritis, carditis, and/or pancreatitis) \\
Bullous IgA dermatosis $(n=1)$ & - Arthralgia, exanthema, and urethritis \\
SDRIFE $(n=1)$ & - Agranulocytosis \\
Vasculitis (after SMX/TRM) $(n=1)$ & - SDRIFE \\
& - malaise and swelling
\end{tabular}

SDRIFE, symmetrical drug-related intertriginous and flexural exanthema; SMX/TRM, sulfamethoxazole/trimethoprim; MDH, multiple drug hypersensitivity; DHR, drug hypersensitivity reaction; DRESS, drug rash with eosinophilia and systemic symptoms.

Flare-up reactions describe the transient and rapid reappearance of identical DHR symptoms when another drug is given while the immune system is still activated by the first DHR (Table 1) [12]. Typically within a few hours after taking a new drug, the preexisting DHR-related skin symptoms become aggravated, with a transient increase in the number of circulating eosinophils and/or liver enzymes. As such rapid flare-up reactions frequently occur days to weeks after the initial manifestation in DRESS, it is not easy to differentiate flare-up reactions from viral reactivations or other complications $[10,13]$. Indeed, viral reactivations themselves may contribute to the clinical symptoms of flare-up reactions [14]. As flare-up reactions normally prompt immediate cessation of the new therapy, the second drug is given only briefly. It is assumed that the second drug does not stimulate the immune system long enough to cause T-cell expansion and permanent sensitization to the new drug. Skin tests to the second drug and drug-induced proliferation as assessed via in vitro LTT remain negative. Importantly, the second drug is tolerated again when the activation of $\mathrm{T}$ cells caused by the initial DHR has resolved. Common elicitors of flare-up reactions are antipyretics such as acetaminophen or antibiotics/antiviral medications.

Some of the cases described by Picard et al. [10] might have been flare-up reactions but others that appeared many days after the acute DRESS and occurred after a longer treatment period may correspond to a true second DHR in the frame of MDH. A careful assessment of the described DRESS cases in the literature revealed that the appearance of new symptoms is common in DRESS [1017]. However, these were often labeled relapses linked to infectious complications and they were seldom recognized as new drug-elicited events. Some of the second reactions were even fatal $[18,19]$.

Multiple Drug Hypersensitivity

\section{Clinical Characteristics of MDH}

We previously described the clinical characteristics of patients with MDH in 2 case series comprising altogether 14 patients $[6,7]$. Here we have extended the number of patients to altogether 31 (see online suppl. Table 1S; see www.karger.com/doi/10.1159/000458725 for all online suppl. material) and summarized the clinical aspects in Table 2. The initial manifestation of $\mathrm{MDH}$ is mostly severe exanthema ( $n=13$, including 1 case of erythroderma) often with some eosinophilia and a moderate elevation of transaminases (ALT and/or AST 2-5 times the upper limit of normal) but not enough to meet the diagnostic criteria for DRESS [20,21]. Twelve out of $31 \mathrm{pa}-$ tients with MDH met the diagnostic criteria for DRESS. A further 3 patients had erythema multiforme major. One patient had initially a bullous IgA dermatosis after metronidazole and ceftriaxone, another had symmetrical drug-related intertriginous and flexural exanthema after allopurinol, and finally one patient had vasculitis after sulfamethoxazole/trimethoprim (Table 2). The eliciting drugs of the first and follow-up DHR of MDH are listed in Table 3.

Severe DHR are accompanied by lymphocytosis with massive lymphocyte activation (lymphoblasts) and this is also one of the main diagnostic criteria for DRESS [20, 21]. This strong lymphocyte activation can persist for weeks or months after drug withdrawal, and it is still present even when the clinical symptoms have disappeared. Our clinical experiences suggest that the presence of these lymphoblasts in the circulation correlates with the ongoing predisposition to react to other drugs, resulting in either short flare-up reactions or further DHR to new drugs [14]. Indeed, 12 out of 31 patients with $\mathrm{MDH}$ reacted immediately to the combination therapy ( 6 of the 12 reacted

Int Arch Allergy Immunol 2017;172:129-138 DOI: $10.1159 / 000458725$ 
Table 3. Drugs involved in $\mathrm{MDH}$

\begin{tabular}{|c|c|}
\hline & $\begin{array}{l}\operatorname{drug}(n=31) \\
\text { amoxicillin }\end{array}$ \\
\hline $3 x$ & $\begin{array}{l}\text { amoxicillin/clavulanic acid, sulfasalazine (sulfapyridine/5- } \\
\text { aminosalicylic acid), sulfamethoxazole/trimethoprim, } \\
\text { phenytoin, carbamazepine, and rifampicin }\end{array}$ \\
\hline $2 \times$ & lidocaine \\
\hline $1 \times$ & $\begin{array}{l}\text { vancomycin, allopurinol, escitalopram, metronidazole/ } \\
\text { ceftriaxone, cefepime, cefuroxime, piperacillin/tazobactam, } \\
\text { and isoniacid }\end{array}$ \\
\hline
\end{tabular}

Follow-up drugs (second or third DHR)

$2 \times$ amoxicillin, sulfamethoxazole/trimethoprim, and budesonide

$1 \times$ phenytoin, lamotrigine, carbamazepine, triamzolam, amitriptyline, pantoprazole, rifampicin, metronidazole, sulfamethoxazole ${ }^{\mathrm{a}}$, ceftobiprole, ceftriaxone, ertapenem, penicillin $\mathrm{G}$, piperacillin/tazobactam, vancomycin, clindamycin, levofloxacin, and ciprofloxacin

Other drugs known to induce $\mathrm{MDH}$ are: antituberculous drugs like pyrazinamide and ethambutol; radiocontrast media, torasemide, furosemide, flucloxacillin, imipenem (and possibly other drugs; the list is not complete). $\mathrm{MDH}$, multiple drug hypersensitivity; DHR, drug hypersensitivity reactions. ${ }^{\text {a }}$ Only single sensitization (not to trimethoprim).

also later) and 13 out of 31 patients reacted within the first 2-6 weeks to 2 or more drugs. On the other hand, 12 out of 31 patients developed a second DHR years after the first DHR; the longest time interval was reported from a 14-year-old boy with carbamazepine-induced DRESS who developed clindamycin-induced exanthema 20 years later. This was also the youngest patient of our case series (online suppl. Table 1S).

The follow-up symptoms can be identical to or different from the first DHR (Table 2). Identical symptoms to the second drug were observed in 8 patients, among whom 5 patients had DRESS again. Two of these had an additional organ involvement, one with pancreatitis and the other with fulminant liver failure [18]. One patient reacted twice with symmetrical drug-related intertriginous and flexural exanthema, first to allopurinol and then to amoxicillin, with a 2-year interval in between. Four patients had repeatedly exanthema.

Most subsequent symptoms in the context of $\mathrm{MDH}$ differed from the first presentation; they changed from DRESS to exanthema or to an isolated drug-induced liver injury. Others developed acute generalized exanthema- tous pustulosis $(n=1)$, erythroderma $(n=2)$, and exanthema with arthralgia or other organ involvements with nephritis, pancreatitis, or agranulocytosis [22] (Table 2). Thus, either fewer or more dangerous symptoms could appear in follow-up DHR manifestations.

The 2 cases of lidocaine-initiated MDH were similar; they reacted initially to lidocaine-containing hemorrhoidal cream with contact dermatitis. They both developed a massive systemic skin reaction with erythema multiforme after subcutaneous application of lidocaine. Strangely enough, both developed as a second DHR a contact allergy to budesonide 9-10 years later, which manifested as localized facial rash/swelling upon inhalation of budesonide and contact dermatitis to cross-reactive corticosteroid-containing creams.

SJS/TEN does not appear as a first manifestation of $\mathrm{MDH}$, but it may occur as a second or third manifestation ( 3 out of 31 patients). This is also in agreement with the report by Picard et al. [10], which showed that only 1 out of 60 patients with SJS/TEN developed symptoms upon exposure to a second drug. Of note, SJS/TEN differs from DRESS in that no lymphocytosis and no evidence of massive cell activation in the circulation is found in most SJS/ TEN patients [23]. Identification of the culprit drug(s) of SJS/TEN is often difficult [24]. One patient even developed first maculopapular exanthema, then DRESS, then acute generalized exanthematous pustulosis, and lastly a fatal TEN to different drugs within a span of 2 months [25].

A controversial issue is the role of herpes viruses in DRESS and MDH. HHV6, Epstein-Barr virus, and cytomegalovirus reactivations can be found in many patients 2-4 weeks after the onset of DRESS [17, 20, 26, 27], but these have not been described in patients with severe exanthema alone, who account for many of the patients with MDH. This, as well as the delayed appearance of herpes virus reactivations in DRESS, suggests that these viral reactivations are not necessary to start an $\mathrm{MDH}$ syndrome. Nevertheless, they may play a role in some individual cases in which recurrent relapses, flare-up reactions, and even new DHR occur [10, 17, 26, 27]. Importantly, the activation of T cells in $\mathrm{MDH}$, which are found years after the acute DHR, cannot be linked to an ongoing cytomegalovirus or HHV6 infection [8].

We observed MDH almost exclusively in patients with T-cell-mediated drug reactions and our explanation of $\mathrm{MDH}$ is based on this T-cell concept. However, there exist cases of IgE-mediated anaphylaxis to structurally distinct drugs. For example, some patients with perioperative anaphylaxis react, on skin tests and in vitro, to biva- 
Table 4. LTT results of patients who had DHR to a combination therapy

\begin{tabular}{|c|c|c|c|}
\hline Total positive LTT & Positive LTT & Positive LTT & Positive LTT \\
\hline $\begin{array}{l}\text { Amoxicillin/clavulanic acid } \\
n=115\end{array}$ & $\begin{array}{l}\text { amoxicillin } \\
64(56)\end{array}$ & $\begin{array}{l}\text { clavulanic acid } \\
12(10)\end{array}$ & $\begin{array}{l}\text { amoxicillin and clavulanic acid } \\
39(34)\end{array}$ \\
\hline $\begin{array}{l}\text { Cotrimoxazole } \\
n=37\end{array}$ & $\begin{array}{l}\text { sulfamethoxazole } \\
16(43)\end{array}$ & $\begin{array}{l}\text { trimethoprim } \\
4(11)\end{array}$ & $\begin{array}{l}\text { sulfamethoxazole and trimethoprim } \\
17(46)\end{array}$ \\
\hline $\begin{array}{l}\text { Piperacillin/tazobactam } \\
n=21\end{array}$ & $\begin{array}{l}\text { piperacillin } \\
7(33)\end{array}$ & $\begin{array}{l}\text { tazobactam } \\
7(33)\end{array}$ & $\begin{array}{l}\text { piperacillin and tazobactam } \\
7(33)\end{array}$ \\
\hline $\begin{array}{l}\text { Sulfasalazine } \\
n=10\end{array}$ & $\begin{array}{l}\text { sulfapyridine } \\
6(60)\end{array}$ & $\begin{array}{l}5 \text {-ASA } \\
0(0)\end{array}$ & $\begin{array}{l}\text { sulfapyridine and 5-ASA } \\
4(40)\end{array}$ \\
\hline Total $(n=183)$ & $93(33-60 \%)$ & $23(0-33 \%)$ & $67(33-46 \%)$ \\
\hline
\end{tabular}

Values are presented as numbers (\%) unless otherwise stated. LTT, lymphocyte transformation tests; DHR, drug hypersensitivity reaction; 5-ASA, 5-aminosalicylic acid; DRESS, drug rash with eosinophilia and systemic symptoms. Thirty-three to forty-six percent of patients had double sensitizations. The frequency of single and double sensitizations in drug-allergic patients during 4 commonly used drug combination therapies is shown. Positive LTT (stimulation index $>3$ ) to the combination therapy were selected from $>2,000$ LTT analyzed over 6 years. Patients with DRESS to the above-mentioned combination therapy were positive in $65-85 \%$ of LTT. ${ }^{a}$ Mostly severe exanthema. ${ }^{\mathrm{b}}$ Mostly DRESS.

lent drugs like chlorhexidine and to neuromuscular blocking agents like rocuronium. While these cases fulfill the formal criteria for MDH, they clearly have a different mechanism and are not linked to severe T-cell reactions. These solely IgE-mediated cases are not discussed in this review.

\section{Simultaneous, Sequential, and Distant Forms of MDH}

Gex-Collet et al. [6] differentiated 2 forms of MDH based on simultaneous or sequential sensitizations leading to DHR. Studer et al. [11] proposed a similar approach; they distinguished MDH patients who developed a sensitization to different substances during the same episode of cutaneous DHR (mostly lasting 2-6 weeks) from MDH patients in whom different substances caused a second DHR in separate episodes. In addition, they differentiated MDH based on DRESS from that which was possibly related to viral replication. Although it is difficult to delineate different triggers in the first episode of DHR, it makes logical sense to differentiate simultaneous from sequential forms of $\mathrm{MDH}$ as the simultaneous forms are often due to therapy with fixed drug combinations (Table 4). In some cases, DHR may occur years later, representing a distant form of $\mathrm{MDH}$.

Multiple Drug Hypersensitivity

\section{Simultaneous}

$\mathrm{MDH}$ syndrome may start with sensitizations to more than one drug at the start of therapy. This simultaneous sensitization occurs if drugs are given in a combination therapy. Examples include sulfamethoxazole combined with trimethoprim (cotrimoxazole), amoxicillin combined with clavulanic acid, and piperacillin combined with tazobactam. The concurrent use of vancomycin with rifampicin, of metronidazole with ceftriaxone, and of antituberculous therapy (e.g., rifampicin and isoniacid) also resulted in simultaneous $\mathrm{MDH}$. Twelve out of 31 patients belonged to this simultaneous subgroup (see online suppl. Table 1S).

When the LTT data of patients with DHR due to combination therapy with at least one positive LTT (stimulation index $>3$ ) over 6 years were analyzed, the frequency of double sensitizations was found to be rather high (33$46 \%$; Table 4). Some of these patients developed a further DHR to another drug later. Occasionally (4 out of 31 patients), a combination therapy was responsible for the second manifestation of MDH (see online suppl. Table 1S).

\section{Sequential}

An initial severe DHR is a risk factor for a flare-up reaction or a second DHR. The first therapy is stopped because of a DHR and the second therapy may be started, often within days, while T cells are still activated. Not infrequent-

Int Arch Allergy Immunol 2017;172:129-138 DOI: $10.1159 / 000458725$ 
ly, the new drug may just elicit a flare-up reaction. However, when the treatment lasts longer, a second, true DHR directed against the alternative drug may develop, resulting in $\mathrm{MDH}$. This was observed in 13 out of $31 \mathrm{MDH}$ patients.

It is not uncommon that more than 2 drugs are involved in $\mathrm{MDH}$ [25]. We repeatedly observed both simultaneous and sequential appearances of DHR occurring in the same patient who reacted to 3-4 different drugs (see online suppl. Table 1S and 2S).

\section{Distant (Long-Interval) $\mathrm{MDH}$}

The distant, long-interval form of MDH occurs when the DHR symptoms appear after the initial DHR has already disappeared. It occurred in 12 out of 31 patients. The interval between the first and second DHR ranged from 2 to 20 years. This implies that a patient with a severe DHR like DRESS may be at risk for developing a second DHR for many years. Whether this represents a preexisting predisposition for the development of $\mathrm{MDH}$ even before the onset of the first DHR or this risk is acquired after the initial DHR is unknown at this stage.

\section{Risk Factors for the Development of MDH}

The majority of MDH develop in patients with DRESS. Consequently, the risk factors involved in eliciting DRESS are also relevant for the development of $\mathrm{MDH}$.

\section{Type of Drug}

Use of a drug that is able to cause a severe T-cell-mediated DHR is a main risk factor. As most MDH start with DRESS, the same drugs involved in DRESS are also involved in $\mathrm{MDH}$. Antiepilepsy medications, sulfonamide antibiotics, and allopurinol are the main causes of DRESS and, not surprisingly, these drugs were also involved in our MDH patients who had DRESS (Table 3). However, drugs that are uncommon causes of DRESS can still be the starting drugs for $\mathrm{MDH}$ if the first reaction was severe.

\section{High Drug Concentration}

Most of the drugs eliciting DRESS are given at relative high daily doses, often exceeding $1 \mathrm{~g} /$ day. The frequent occurrence of $\mathrm{MDH}$ to combination therapy may also be due to the high individual drug doses used in these combinations (see online suppl. Table 3S).

\section{Combination Therapy}

DHR to both components of a fixed combination therapy like amoxicillin/clavulanic acid, cotrimoxazole (sul- famethoxazole/trimethoprim), and piperacillin/tazobactam is rather common. Table 4 summarizes the LTT results extracted from our database covering 6 years $(2,000$ LTT; Table 4). While sulfasalazine is not a combination drug per se, it is metabolized to sulfapyridine and 5-aminosalicylic acid and double sensitizations to both components occur (Table 4). All of these medications are also given in gram quantities (see online suppl. Table 3S). The frequency of double sensitizations is higher than the frequency of sensitization to the less "immunogenic" compounds (33-46 vs. $0-33 \%$; Table 4 ). This suggests that the reactivity to the less immunogenic compound (e.g. clavulanic acid in amoxicillin/clavulanic acid) is enhanced if an immune reaction to the more immunogenic compound (i.e., amoxicillin) occurs simultaneously.

Similar to fixed combination therapy is the situation with antituberculous therapy, where treatment schemes also rely on a high dose of isoniazid, rifampicin, pyrazinamide, and either ethambutol or streptomycin together. In this instance, a simultaneous reactivity to 2 or more compounds can develop (see online suppl. Table 1S).

\section{Longer-Lasting Treatment}

Many of the therapies causing DRESS/MDH are given for more than 10-20 days. This prolonged treatment seems to increase $\mathrm{T}$-cell reactions to the drug in general and it is also a risk factor for DRESS/MDH, especially if given in high doses. Therefore, MDH syndrome appears in patients on long-term, high-dose therapy for conditions such as complicated infections (e.g., for prosthetic joint infection) or epilepsy. On the other hand, many drugs used for hypertension or hypercholesterolemia are not linked to DRESS/MDH in spite of continuous treatment. Most of these drugs are given at lower doses (typically $<50 \mathrm{mg}$ /day) and are not known or infrequent causes of DHR.

\section{No Human Leukocyte Antigen Linkage to $\mathrm{MDH}$ Syndrome}

Severe reactions (SIS/TEN/DRESS) to some drugs are linked to certain human leukocyte antigen (HLA) alleles $[28,31]$. These linkages can be explained by an off-target activity of a particular drug to a certain HLA protein [32]. For example, carbamazepine binds with a rather high affinity to HLA-B*15:02, oxypurinol binds to HLA-B*58: 01 , and abacavir binds to HLA-B*57:01 [28-31]. The starting DHR of an $\mathrm{MDH}$ syndrome can consequently be linked to a drug that has an HLA linkage. However, the $\mathrm{MDH}$ itself, presenting as a syndrome with multiple DHR, is not linked to a certain HLA. An exception is if 
the HLA-protein involved in the first DHR also binds to drugs involved in the follow-up DHR. For example, an individual who develops carbamazepine-induced DHR due to the drug binding to HLA-B*15:02 may also develop subsequent DHR to lamotrigine or phenytoin which may also bind to HLA-B*15:02 [33]. Further analysis of HLA and of other genetic predispositions is needed as some data have indicated a familiar predisposition [3].

\section{Patho-Mechanism of MDH}

As there is no animal model for $\mathrm{MDH}$, in vitro data rely on analysis of blood samples and biopsies of affected patients. In a few cases analyzed, lymphocytosis and the presence of activated $\mathrm{T}$ cells in the circulation (CD3+, CD4+ and/or CD8+, and HLA-DR+) or tissue (liver) have been found [18, 34]. The study of Daubner et al. [8] investigated the question of whether $\mathrm{T}$ regulatory cells

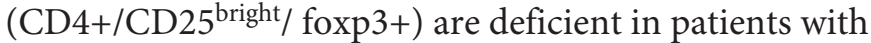
$\mathrm{MDH}$ or not. Seven MDH patients in remission, 6 patients with a prior monoallergy, and 6 healthy controls were recruited and analyzed. Their in vitro reactivity to tetanus toxoid and various drugs (mainly antibiotics and antiepileptics) was analyzed by depleting and selectively readding $\mathrm{CD} 4+, \mathrm{CD} 25^{\text {bright }}$, foxp3+ $\mathrm{T}$ regulatory cells in proliferation assays. All $7 \mathrm{MDH}$ patients showed a drugspecific reactivity in in vitro proliferation assays years after the acute event. Interestingly, no functional deficiency of $\mathrm{T}$ regulatory cells was observed either in the drug-specific assays or in the control cultures with tetanus toxoid as the antigen.

The surprising result of this study is that patients with $\mathrm{MDH}$ still showed signs of permanent cell activation in the circulation years after the acute event. While the massive T-cell stimulation with circulating lymphoblasts disappeared within weeks to months after the acute DHR, some signs of T-cell activation detectable by flow cytometry persisted longer. This persistent $\mathrm{T}$-cell activation of $\mathrm{MDH}$ patients was characterized by $\mathrm{CD} 4+, \mathrm{CD} 25^{\mathrm{dim}}$ (the study focused on CD4 cell reactions only), which contained an activated T-cell subset (PD-1+/CD38+) and this $\mathrm{PD}-1+/ \mathrm{CD} 38+$ subset contained the drug-reactive $\mathrm{T}$ cells. Patients with a monoallergy did not have these CD4+, CD25 dim , CD38+, and PD-1+ T cells [8]. Initially it was speculated that the continued CD38+ and PD-1+ expression within the $\mathrm{CD} 4+, \mathrm{CD} 25^{\mathrm{dim}}$ cell fraction might be due to an ongoing infection by endogenous herpes viruses, as the $\mathrm{PD} 1+/ \mathrm{CD} 38+$ phenotype was also ob-

Multiple Drug Hypersensitivity served in chronic herpes virus infections $[35,36]$. However, a viral analysis of the patients failed to document an ongoing herpes virus (cytomegalovirus and HHV6) infection.

\section{Unresolved Questions}

$\mathrm{MDH}$ is a new syndrome, and many clinical and immunological questions are unsolved.

How do drugs stimulate T cells in MDH? The initial DHR - a DRESS or severe exanthema - appears to be initiated by $\mathrm{p}$-i-mediated T-cell stimulations where the drug directly binds noncovalently to a particular HLA protein itself with a substantial affinity (p-i HLA) [37-41]. Classical hapten-dependent reactions with covalent binding of the drug to the HLA-presented peptide were repeatedly excluded [31, 37-42]. In sulfamethoxazole-induced DHR, the drug may bind to the TCR (p-i-TCR) $[43,44]$. Thus the initial manifestation of $\mathrm{MDH}$ appears to be mostly p-i mediated.

A second feature of $\mathrm{MDH}$ is the strengths of the reaction - both in vivo (e.g., DRESS) and - if tested - also in vitro. The T-cell proliferations to a single drug as assessed by LTT revealed a polyclonal stimulation with stimulation indices $>50$ (normally $<2$ ) (see online suppl. Table $2 S$ ), which was stronger than the stimulation by a large protein antigen like tetanus toxoid and sometimes even exceeded the mitogen stimulation with phytohemagglutinin or pokeweed mitogen. This massive, drug-induced proliferation in a 6- to 7-day culture is reminiscent of proliferations observed in mixed leukocyte reactions. This would be consistent with the allo-immune hypothesis of DHR which postulates that severe DHR are due to $\mathrm{p}-\mathrm{i}$ stimulations resulting in allo-like immune stimulations $[32,45]$. It hypothesizes that drug binding to HLA modifies the HLA-peptide complex and makes it look like an allo-HLA structure, which then elicits a strong, polyclonal T-cell stimulation. This has been documented in the abacavir model, where the peptide-abacavir-HLA$B^{*} 57: 01$ complex acquires the conformation of the \{peptide-HLA-B*58:01\} complex [32]. If one applies this concept to severe DHR in general, MDH may start with a massive, graft-versus-host disease-like immune stimulation, which in the case of $\mathrm{MDH}$ somehow persists for years (elevated PD-1/CD38+ T cells). Follow-up reactions in $\mathrm{MDH}$ appear to be mostly p-i stimulations as well, but hapten-dependent immune stimulations may also occur. Further studies on the patho-mechanism of $\mathrm{MDH}$ and its long-lasting T-cell reactivity are needed.

Int Arch Allergy Immunol 2017;172:129-138 DOI: 10.1159/000458725 
Table 5. Possible measures to avoid flare-up reactions and further DHR

Restrict the use of drugs in patients with ongoing severe DHR (mainly DRESS) as much as possible.

If new drugs are needed, choose drugs that are effective at low doses ( $<50 \mathrm{mg} /$ day $)$.

Replace antipyretics with physical measures (e.g., wet compresses instead of acetaminophen).

Use antibiotics only for therapy, not for prophylaxis.

Suppress the immune stimulation by corticosteroid therapy (oral or i.v. prednisolone is normally tolerated). For example, $0.3-0.5 \mathrm{mg} / \mathrm{kg} /$ day of prednisolone equivalent for $2-7$ days, followed by a stepwise reduction, dependent on the amount of circulating lymphoblasts.

Alternatively, attempt to create a therapy-free interval for days to weeks. Keep these measures as long as the proportion of massively activated lymphocytes (lymphoblasts) in the circulation is elevated ${ }^{\mathrm{a}}$.

DHR, drug hypersensitivity reaction; DRESS, drug rash with eosinophilia and systemic symptoms. These measures are based on clinical experience and the risk factors described in the text. ${ }^{\text {a }}$ Standard values of lymphoblasts differ from lab to lab. A substantial decrease should be noted.

It is difficult to comprehend why stimulation by one drug would pave the way for an additional reaction to other drugs. This is the case in simultaneous MDH to both components of a fixed combination therapy (Table 4). As already mentioned, the drug-reactive T cells of $\mathrm{MDH}$ patients are specific to the particular drug and they are not cross-reactive. One explanation might be that an ongoing T-cell activation is a risk factor for a second DHR; similar to the costimulatory effect of viral infections (Epstein-Barr virus and HIV) on the manifestation of a DHR, the T-cell activation of the first DHR may lower the threshold of reactivity to a second drug [8].

What keeps the T cells of MDH patients in "alarm mode" for years and what facilitates a second sensitization? According to the allo-immune model of DHR, the initial allo-like immune reaction (e.g., DRESS) might also include $\mathrm{T}$ cells cross-reactive for autoantigens, which remain stimulated, even when the drug has been removed. The MDH might thus correspond to a chronic graft-versus-host disease-like stimulation. Indeed, the CD4+, CD$25^{\mathrm{dim}}, \mathrm{CD} 38+$, and PD-1+ T cells found in $\mathrm{MDH}$ are also found in chronic graft-versus-host disease [45].

\section{Conclusion}

$\mathrm{MDH}$ is a rather novel syndrome which is characterized by DHR to various structurally different drugs. It is initiated by severe T-cell reactions (mostly severe exanthema and DRESS), which appear to have a long-lasting effect on the patient's immune system.

$\mathrm{MDH}$ is often seen as a complication of an ongoing DRESS with recurrence of some of the DRESS symptoms over time [10,11]. However, clinical data has shown that $\mathrm{MDH}$ can start outside of DRESS $[8,10]$ and the clinical course of the second and third DHR is often different to DRESS (Table 3). Thus, not the disease DRESS itself but rather the strengths of the T-cell stimulation seems to be the decisive factor for development of a MDH. Since SJS/ TEN is not a risk factor for developing $\mathrm{MDH}$, the type of immune stimulation (probably a more CD4-biased stimulation with strong T-cell expansion and thus lymphocytosis and circulating lymphoblasts) might be crucial as well.

The chronicity of the MDH syndrome is documented by the long time interval between DHR manifestations (up to $>20$ years) and the presence of permanently activated $\mathrm{T}$ cells expressing PD-1+, CD38+ in the circulation for years. These activated T cells were found in $\mathrm{MDH}$ with simultaneous, sequential, or distant DHR appearances. $\mathrm{MDH}$ thus challenges the conventional concept of DHR as an acute, drug-dependent reaction; an initial severe DHR may alter the immune system permanently and switch it to a chronic immune disorder.

Whether the presence of permanently activated $\mathrm{T}$ cells is detrimental to health is not known. A high percentage of PD1+, CD38+ circulating T cells has also been found in other chronic diseases such as graft-versus-host disease [45] and chronic herpes virus infections $[35,36]$. In the latter it was linked to a reduced life span of the affected persons [46].

We did not use provocation tests to define $\mathrm{MDH}$. Provocation tests are contraindicated in severe DHR and potentially problematic in patients with a tendency to react to more drugs. Nevertheless, they would be helpful in $\mathrm{MDH}$ due to a combination therapy such as cotrimoxazole, as the conclusion that both drugs (e.g., sulfamethoxazole and trimethoprim) are involved in eliciting DHR is only based on positive skin and/or in vitro tests to both drugs of the combination therapy (Table 4).

Patients with MDH present a diagnostic and therapeutic dilemma for the treating physician. The symptoms are often similar to infectious complications and may not be linked to a new DHR [13]. It is difficult to know which 
antibiotic can be given safely to a patient with active DRESS, given that up to $25 \%$ of patients may develop an $\mathrm{MDH}$ [10]. It is possible that there are some drugs or antibiotics that pose a lower risk for the development of new DHR. Indeed, not every drug to which the patient was exposed was positive on LTT (see example in online suppl. Table 2S). Such data need to be collected and evaluated.

Based on our clinical experience, and the risk factors described above, we propose the following actions to lower the risk of the development of MDH in patients with severe T-cell-mediated reactions: (1) minimize the use of further drugs; (2) omit antipyretics; (3) avoid antibiotics unless they are absolutely indicated; (4) if needed, choose drugs that can be given at a lower dose (such as possibly $<50 \mathrm{mg}$ /day); (5) dampen the hyperactivation of the immune system by steroids (e.g., $0.3-0.5 \mathrm{mg} / \mathrm{kg} /$ day of a prednisolone equivalent for 2 to $>7$ days with a slow dose reduction - the amount of immunosuppression required might be monitored by evaluating the amount of circulating lymphoblasts; and (6) try to create a therapy-free interval for days to weeks (Table 5).

Research on drug hypersensitivity relies on clinical and in vitro analysis of patients, as animal models are not available. The study of a new drug hypersensitivity-relat- ed syndrome like $\mathrm{MDH}$ is therefore difficult, in particular if it is rare. The description of $\mathrm{MDH}$ as an own syndrome is in its infancy, and many of the data presented in this review are still clinical observations that need to be verified, most likely in multicenter studies. Both clinical and immunological studies might be done in patients with DRESS, as these represent a high-risk group for $\mathrm{MDH}$ [10]. However, also the double sensitization in combination therapy appears to be frequent enough to allow a systematic analysis (Table 4). The value of determining $\mathrm{CD} 4+, \mathrm{CD} 25^{\mathrm{dim}}, \mathrm{PD}-1+, \mathrm{CD} 38+$ as a marker for $\mathrm{MDH}$ patients needs to be confirmed, as does the role of activated CD8+ T cells, which was not addressed in the study by Daubner et al. [8]. An important question is whether activated $\mathrm{T}$ cells can already be found in potential $\mathrm{MDH}$ patients, i.e., before the second (or third) DHR takes place. Finally, how long these T cells remain in the circulation and whether the permanent presence of these activated $\mathrm{T}$ cells in the circulation has a deleterious effect on general health needs to be clarified [46].

\section{Disclosure Statement}

The authors declare no conflict of interests.

\section{References}

1 Sullivan TJ, Remedios C, Ong MD, Gilliam LK: Studies of the multiple drug allergy syndrome. J Allergy Clin Immunol 1989;83:270.

2 Attaway NJ, Jasia M, Sullivan T: Familial drug allergy. J Allergy Clin Immunol 1991;87:227.

3 Kurtz KM, Beatty TL, Adkinson NF Jr: Evidence for familial aggregation of immunologic drug reactions. J Allergy Clin Immunol 2000;105:184-185.

4 Asero R: Multiple sensitivity to NSAID. Allergy 2000;55:893-894.

5 Schiavino D, Nucera E, Roncallo C, Pollastrini E, De Pasquale T, Lombardo C, et al: Multiple-drug intolerance syndrome: clinical findings and usefulness of challenge tests. Ann Allergy Asthma Immunol 2007;99:136142.

6 Gex-Collet C, Helbling A, Pichler WJ: Multiple drug hypersensitivity - proof of multiple drug hypersensitivity by patch and lymphocyte transformation tests. J Investig Allergol Clin Immunol 2005;15:293-296.

7 Neukomm CB, Yawalkar N, Helbling A, Pichler WJ: T-cell reactions to drugs in distinct clinical manifestations of drug allergy. J Investig Allergol Clin Immunol 2001;11:275284.

Multiple Drug Hypersensitivity
8 Daubner B, Groux-Keller M, Hausmann OV, Kawabata T, Naisbitt DJ, Park BK, Wendland T, Lerch M, Pichler WJ: Multiple drug hypersensitivity: normal Treg cell function but enhanced in vivo activation of drug-specific $\mathrm{T}$ cells. Allergy 2012;67:58-66.

9 Beeler A, Engler O, Gerber BO, Pichler WJ: Long-lasting reactivity and high frequency of drug-specific $\mathrm{T}$ cells after severe systemic drug hypersensitivity reactions. J Allergy Clin Immunol 2006;117:455-462.

10 Picard D, Vellar M, Janela B, Roussel A, Joly $P$, Musette P: Recurrence of drug-induced reactions in DRESS patients. J Eur Acad Dermatol Venereol 2015;801-804.

11 Studer M, Waton J, Bursztejn AC, AimoneGastin I, Schmutz JL, Barbaud A: Does hypersensitivity to multiple drugs really exist? Ann Dermatol Venereol 2012;139:375-380.

12 Pichler WJ, Daubner B, Kawabata T: Drug hypersensitivity: flare-up reactions, cross-reactivity and multiple drug hypersensitivity. J Dermatol 2011;38:216-221.

13 Lukas J-W, Schnyder B, Helbling A, Fricker M, Helbing K, Schüller A, Wochner A, Pichler WJ: Flare up reactions in severe drug hypersensitivity: infection or ongoing T-cell hyper- responsiveness? Clin Case Rep, DOI: 10.1002/ ccr3.346.

14 Mardivirin L, Valeyrie-Allanore L, BranlantRedon E, Beneton N, Jidar K, Barbaud A, Crickx B, Ranger-Rogez S, Descamps V: Amoxicillin-induced flare in patients with DRESS (drug reaction with eosinophilia and systemic symptoms): report of seven cases and demonstration of a direct effect of amoxicillin on human herpesvirus 6 replication in vitro. Eur J Dermatol 2010;20:68-73.

15 Ben m'rad M, Leclerc-Mercier S, Blanche P, Franck N, Rozenberg F, Fulla Y, Guesmi M, Rollot F, Dehoux M, Guillevin L, Moachon L: Drug-induced hypersensitivity syndrome: clinical and biologic disease patterns in $24 \mathrm{pa}$ tients. Medicine (Baltimore) 2009;88:131-140.

16 Ang CC, Wang YS, Yoosuff EL, Tay YK: Retrospective analysis of drug-induced hypersensitivity syndrome: a study of 27 patients. J Am Acad Dermatol 2010;63:219-227.

17 Kano Y, Shiohara T: The variable clinical picture of drug-induced hypersensitivity syndrome/drug rash with eosinophilia and systemic symptoms in relation to the eliciting drug. Immunol Allergy Clin North Am 2009; 29:481-501. 
18 Mennicke M, Zawodniak A, Keller M, Wilkens L, Yawalkar N, Stickel F, Keogh A, Inderbitzin D, Candinas D, Pichler WJ: Fulminant liver failure after vancomycin in a sulfasalazine-induced DRESS syndrome: fatal recurrence after liver transplantation. Am J Transplant 2009;9:2197-2202.

19 Short K, Syn WK, Haydon G: Sulphasalazineinduced hypersensitivity syndrome: a relapsing disorder and the role of human herpes virus-6. Eur J Gastroenterol Hepatol 2007;19: 181-182.

20 Shiohara T, Iijima M, Ikezawa Z, Hashimoto $\mathrm{K}$ : The diagnosis of a DRESS syndrome has been sufficiently established on the basis of typical clinical features and viral reactivations. Br J Dermatol 2007;156:1083-1084.

21 Kardaun SH, Sekula P, Valeyrie-Allanore L, Liss Y, Chu CY, Creamer D, Sidoroff A, Naldi L, Mockenhaupt M, Roujeau JC; RegiSCAR study group: Drug reaction with eosinophilia and systemic symptoms (DRESS): an original multisystem adverse drug reaction - results from the prospective RegiSCAR study. $\mathrm{Br} J$ Dermatol 2013;169:1071-1080.

22 Wendland T, Daubner B, Pichler WJ: Ceftobiprole associated agranulocytosis after drug rash with eosinophilia and systemic symptoms induced by vancomycin and rifampicin. Br J Clin Pharmacol 2011;71:297-300.

23 Bagot M, Charue D, Heslan M, Wechsler J, Roujeau JC, Revuz J: Impaired antigen presentation in toxic epidermal necrolysis. Arch Dermatol 1993;129:721-727.

24 Porebski G, Pecaric-Petkovic T, Groux-Keller M, Bosak M, Kawabata TT, Pichler WJ: In vitro drug causality assessment in StevensJohnson syndrome - alternatives for lymphocyte transformation test. Clin Exp Allergy 2013;43:1027-1037.

25 Chularojanamontri L, Tuchinda P, Srinoulprasert Y, Kulthanan K, Pichler WJ: Sequential appearance of MPE, DRESS, AGEP and SIS/TEN in the same patient. Int J Basic Clin Pharmacol 2016;5:2688-2691.

26 Seitz CS, Pfeiffer P, Raith P, Bröcker EB, Trautmann A: Anticonvulsant hypersensitivity syndrome: cross-reactivity with tricyclic antidepressant agents. Ann Allergy Asthma Immunol 2006;97:698-702.

27 Inadomi T: Drug rash with eosinophilia and systemic symptoms (DRESS): changing carbamazepine to phenobarbital controlled epilepsy without the recurrence of DRESS. Eur J Dermatol 2010;20:220-222.

28 Zhou P, Zhang S, Wang Y, Yang C, Huang J: Structural modeling of HLA-B*1502/peptide/ carbamazepine/T-cell receptor complex architecture: implication for the molecular mechanism of carbamazepine-induced Stevens-Johnson syndrome/toxic epidermal necrolysis. J Biomol Struct Dyn 2015;14:1-12.
29 McCormack M, Alfirevic A, Bourgeois S, Farrell JJ, Kasperavičiūtè D, Carrington $\mathrm{M}$, Sills GJ, Marson T, Jia X, de Bakker PI, Chinthapalli K, Molokhia M, Johnson MR, O'Connor GD, Chaila E, Alhusaini S, Shianna KV, Radtke RA, Heinzen EL, Walley N, Pandolfo M, Pichler W, Park BK, Depondt C, Sisodiya SM, Goldstein DB, Deloukas P, Delanty N, Cavalleri GL, Pirmohamed M: HLA-A*3101 and carbamazepine-induced hypersensitivity reactions in Europeans. N Engl J Med 2011; 364:1134-1143.

30 Hung SI, Chung WH, Liou LB, Chu CC, Lin M, Huang HP, Lin YL, Lan JL, Yang LC, Hong HS, Chen MJ, Lai PC, Wu MS, Chu CY, Wang $\mathrm{KH}$, Chen $\mathrm{CH}$, Fann CS, Wu JY, Chen YT: HLA-B*5801 allele as a genetic marker for severe cutaneous adverse reactions caused by allopurinol. Proc Natl Acad Sci USA 2005; 102:4134-4139.

31 Illing P, Vivian JP, Dudek NL, Kostenko L, Chen Z, Bharadwaj M, Miles JJ, Kjer-Nielsen L, Gras S, Williamson NA, Burrows SR, Purcell AW, Rossjohn J, McCluskey J: Immune self-reactivity triggered by drug-modified HLA-peptide repertoire. Nature 2012;486: 554-558.

32 Adam J, Wuillemin N, Watkins S, Jamin H, Eriksson K, Villiger P, Fontana S, Pichler WJ, Yerly $\mathrm{D}$ : Abacavir induced $\mathrm{T}$ cell reactivity from drug naive individuals shares features of allo-immune responses. PLoS One 2014; 9:e95339.

33 Hung SI, Chung WH, Liu ZS, Chen $\mathrm{CH}$, Hsih MS, Hui RC, Chu CY, Chen YT: Common risk allele in aromatic antiepileptic-drug induced Stevens-Johnson syndrome and toxic epidermal necrolysis in Han Chinese. Pharmacogenomics 2010;11:349-356.

34 Hari Y, Frutig-Schnyder K, Hurni M, Yawalkar N, Zanni MP, Schnyder B, Kappeler A, von Greyerz S, Braathen LR, Pichler WJ: T cell involvement in cutaneous drug eruptions. Clin Exp Allergy 2001;31:1398-1408.

35 Chiu C, McCausland M, Sidney J, Duh FM, Rouphael N, Mehta A, Mulligan M, Carrington $M$, Wieland A, Sullivan NL, Weinberg A, Levin MJ, Pulendran B, Peters B, Sette A, Ahmed R: Broadly reactive human CD8 T cells that recognize an epitope conserved between VZV, HSV and EBV. PLoS Pathog 2014;10:e1004008.

36 Dirks J, Egli A, Sester U, Sester M, Hirsch HH: Blockade of programmed death receptor-1 signaling restores expression of mostly proinflammatory cytokines in anergic cytomegalovirus-specific $\mathrm{T}$ cells. Transpl Infect Dis 2013;15:79-89.
37 Wei CY, Chung WH, Huang HW, Chen YT, Hung SI: Direct interaction between HLA-B and carbamazepine activates $\mathrm{T}$ cells in patients with Stevens-Johnson syndrome. J Allergy Clin Immunol 2012;129:1562-1569.

38 Yang CW, Hung SI, Juo CG, Lin YP, Fang WH, Lu IH, Chen ST, Chen YT: HLA-B*1502 bound peptides: implications for the pathogenesis of carbamazepine-induced StevensJohnson syndrome. J Allergy Clin Immunol. 2007;120:870-877.

39 Yun J, Marcaida MJ, Eriksson KK, Jamin H, Fontana S, Pichler WJ, Yerly D: Oxypurinol directly and immediately activates the drugspecific $T$ cells via the preferential use of HLA-B*58:01. J Immunol 2014;192:29842993.

40 Wuillemin N, Adam J, Fontana S, Krahenbuhl S, Pichler WJ, Yerly D: HLA haplotype determines hapten or $\mathrm{p}-\mathrm{i} \mathrm{T}$ cell reactivity to flucloxacillin. J Immunol 2013;190:49564964.

41 Naisbitt DJ, Britschgi M, Wong G, Farrell J, Depta JPH, Chadwick DW, Pichler WJ, Pirmohamed M, Park BK: Hypersensitivity reactions to carbamazepine: characterization of the specificity, phenotype and cytokine profile of drug-specific T-cell clones. Mol Pharm March 2003;63:732-741.

42 Naisbitt DJ, Britschgi M, Wong G, Farrell J, Depta JPH, Chadwick DW, Pichler WJ, Pirmohamed M, Park BK: Characterization of drug-specific T-cells in lamotrigine hypersensitivity. J Allergy Clin Immunol 2003;111: 1393-1403.

43 Schnyder B, Burkhart C, Schnyder-Frutig K, von Greyerz S, Naisbitt DJ, Pirmohamed M, Park BK, Pichler WJ: Recognition of sulfamethoxazole and its reactive metabolites by drug-specific CD4+ T cells from allergic individuals. J Immunol 2000;164:6647-6654.

44 Watkins S, Pichler WJ: Activating interactions of sulfanilamides with $\mathrm{T}$ cell receptors. Open J Immunol 2013:3:139-157.

45 Pichler WJ, Adam J, Watkins S, Wuillemin N, Yun J, Yerly D: Drug hypersensitivity: how drugs stimulate $\mathrm{T}$ cells via pharmacological interaction with immune receptors. Int Arch Allergy Immunol 2015;168:13-24.

46 Blazar BR, Carreno BM, Panoskaltsis-Mortari $A$, et al: Blockade of programmed death-1 engagement accelerates graft-versus-host disease lethality by an IFN- $\gamma$-dependent mechanism. J Immunol 2003;171:1272-1277.

47 Bauer ME, Fuente M: The role of oxidative and inflammatory stress and persistent viral infections in immunosenescence. Mech Ageing Dev 2016;158:27-37. 